\title{
Tractional Retinal Detachment in a Patient With Waldenström's Macroglobulinemia
}

\author{
Anastasia Tsiogka ${ }^{1}$, Aristotelis Karamaounas ${ }^{2}$, Evangelia Papakonstantinou ${ }^{2}$, Petros Petrou Sr. ${ }^{2}$ \\ 1. Ophthalmology, 401 General Military Hospital, Athens, GRC 2. Ophthalmology, "G. Gennimatas" General Hospital of \\ Athens, Athens, GRC
}

Corresponding author: Anastasia Tsiogka, anastasia.tsioga@gmail.com

\begin{abstract}
An 86-year-old man with Waldenström's macroglobulinemia and a history of acute retinal necrosis (four years ago) presented with reduced visual acuity in his right eye of three days' duration. He developed epiretinal membrane and tractional retinal detachment, which were treated successfully. Epiretinal membrane and tractional retinal detachment usually occur one to two months after the onset of retinitis. In our case, this happened four years after the diagnosis of acute retinal necrosis syndrome, prophylactic vitrectomy, and successful treatment of acute retinal necrosis syndrome in a patient with Waldenström's macroglobulinemia.
\end{abstract}

Categories: Ophthalmology, Infectious Disease, Oncology

Keywords: acute retinal necrosis, epiretinal membrane, tractional retinal detachment

\section{Introduction}

It is commonly known that patients with cancer have an increased risk of opportunistic infections due to an immune dysfunction, which may be caused by antineoplastic chemotherapy, an underlying malignancy, or invasive procedures performed during supportive care [1]. Waldenström's macroglobulinemia (WM) is a lymphoplasmacytic lymphoma, a malignant disorder that causes overproduction of monoclonal immunoglobulin $\mathrm{M}[2]$. A common ocular symptom that occurs in WM patients is blurred vision due to retinal bleeding. Funduscopic examination in these patients commonly reveals distended and tortuous retinal veins and multiple flame-shaped or punctate retinal hemorrhages [3].

Review began 12/15/2020 Review ended 12/26/2020 Published 01/02/2021

\section{() Copyright 2021}

Tsiogka et al. This is an open access article distributed under the terms of the Creative Commons Attribution License CC-BY 4.0., which permits unrestricted use, distribution, and reproduction in any medium, provided the original author and source are credited.
Cytomegalovirus (CMV) is a well-known cause of retinitis in immunosuppressed patients [2]. In addition, CMV is an infrequent cause of acute retinal necrosis (ARN), which is a rare cause of blindness in healthy adults [4]. Patients typically present with vitritis, occlusive vasculitis, and peripheral retinal necrosis, with an average duration of symptoms of 15 days [5]. Rhegmatogenous retinal detachment (RRD) is a common complication of ARN, occurring in 50\%-75\% of eyes and manifesting one to two months after the onset of retinitis [6].

We report a case of a patient with WM and CMV-related ARN who developed tractional retinal detachment (TRD) four years after the diagnosis and successful treatment of ARN syndrome.

\section{Case Presentation}

An 86-year-old male was referred to our vitreoretinal clinic, with reduction of vision in the right eye for 24 hours. His medical history included treated WM. His family history was unremarkable. His ocular history included a previous vitrectomy in the same eye four years ago for polymerase chain reaction confirmed CMV-related ARN. At that point, the patient was treated with two intravitreal injections of ganciclovir followed by oral ganciclovir for three months. His visual acuity was 10/10 in both eyes until presentation.

Best corrected distance visual acuity was 4/10 in the right eye and 10/10 in the left eye (Snellen chart). Anterior segment examination was unremarkable, and fundus examination revealed a tractional macula-off retinal detachment (RD) (Figure 1). 


\section{Cureus}

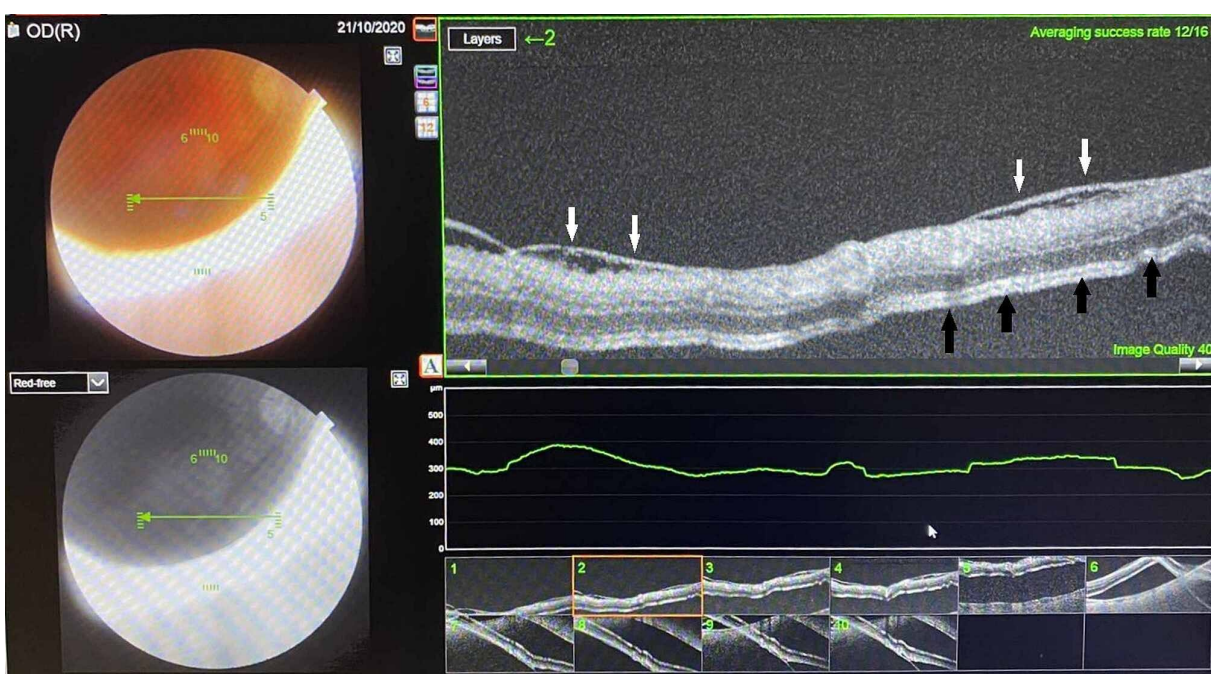

\section{FIGURE 1: Optical coherence tomographic image demonstrating the epiretinal membrane (white arrows) and the tractional retinal detachment (black arrows).}

The patient underwent $25 \mathrm{G}$ three-port pars plana vitrectomy with extensive epiretinal membrane (ERM) peeling and $20 \%$ sulfur hexafluoride gas injection (although a retinal break was not found, gas was used in order to facilitate subretinal fluid absorption). Three months postoperatively, the retina was flat and the visual acuity improved to $8 / 10$.

\section{Discussion}

ARN is a rare cause of vision loss in adults, which is caused by human herpes viruses (varicella-zoster virus, herpes simplex virus types 1 and 2, and rarely CMV and Epstein-Barr virus) [6]. It can affect

immunocompetent or immunosuppressed patients of either gender at any age. In 1971, Urayama et al. first recognized a syndrome of acute panuveitis with retinal periarteritis progressing to diffuse necrotizing retinitis and $\mathrm{RD}[6]$.

The presenting symptoms are blurry vision, irritation, redness, photophobia, periorbital pain, and floaters in the affected eye. Funduscopy reveals focal and well-demarcated areas of rapid retinal necrosis of the peripheral retina, evidence of occlusive vasculopathy, and inflammatory reaction in the vitreous and anterior chamber episcleritis, scleritis, or keratic precipitates [6]. Optic nerve involvement is characterized by optic neuritis and limits the final visual potential [7].

Complications include cystoid macular edema, reproliferation, and RRD, which is a frequent complication with a poor prognosis. In the acute phase of ARN, there is an increase in vitreous turbidity due to the massive breakdown of the blood-ocular barrier, which leads to the formation of membranes and the development of severe proliferative vitreoretinopathy [7]. RRD with ARN occurs in more than $50 \%$ of eyes, due to severe retinal ischemia and vitreous organization. It is a serious late complication, which manifests one to two months after the onset of retinitis $[6,8]$ and usually results in severe visual loss. RD usually develops as a result of retinal breaks located at the junction of the involved and uninvolved retina. These breaks are often located posteriorly and may be quite large. Both situations may create complex combined tractional and rhegmatogenous RD [9].

Prophylactic laser photocoagulation and prophylactic vitrectomy were proposed as two methods for preventing RD in ARN syndrome. Laser photocoagulation is aimed at reducing the risk of RRD by inducing retinal scarring at the central border of the necrotic retina [5]. This method still remains controversial as a way to prevent RD, and its use is limited by vitreous opacity and other complications [7]. Vitrectomy may help eliminate inflammatory factors, prevent lesions from occurring and extending, relieve vitreoretinal traction, and prevent RRD. Prophylactic vitrectomy significantly improves the anatomical and visual prognoses and seems to prevent RRD in cases with ARN [10].

Our patient developed ERM and TRD four years after the diagnosis and treatment of ARN syndrome, for which we performed a prophylactic vitrectomy. To our knowledge, no similar case of ARN and late onset of TRD after prophylactic vitrectomy has ever been mentioned in the literature. More studies are necessary to elucidate the possible mechanism of traction caused by the remaining peripheral vitreous after prophylactic vitrectomy in eyes with ARN syndrome. 


\section{Conclusions}

ARN syndrome is a rare cause of vision loss in adults, which is caused by human herpes viruses. It presents with blurry vision, irritation, redness, photophobia, periorbital pain, and floaters in the affected eye. RD is a serious complication, which occurs in more than $50 \%$ of eyes, manifesting one to two months after the onset of retinitis and usually resulting in severe visual loss. A late onset of TRD, four years after the diagnosis and treatment of ARN syndrome, is possible even after prophylactic vitrectomy.

\section{Additional Information}

\section{Disclosures}

Human subjects: Consent was obtained by all participants in this study. Conflicts of interest: In compliance with the ICMJE uniform disclosure form, all authors declare the following: Payment/services info: All authors have declared that no financial support was received from any organization for the submitted work. Financial relationships: All authors have declared that they have no financial relationships at present or within the previous three years with any organizations that might have an interest in the submitted work. Other relationships: All authors have declared that there are no other relationships or activities that could appear to have influenced the submitted work.

\section{References}

1. Safdar A, Armstrong D: Infectious morbidity in critically ill patients with cancer . Crit Care Clin. 2001, 17:531-70. 10.1016/s0749-0704(05)70198-6

2. Gertz MA: Waldenström macroglobulinemia: 2013 update on diagnosis, risk stratification, and management . Am J Hematol. 2013, 88:703-11. 10.1002/ajh.23472

3. Orellana J, Friedman AH: Ocular manifestations of multiple myeloma, Waldenström's macroglobulinemia and benign monoclonal gammopathy. Surv Ophthalmol. 1981, 26:157-69. 10.1016/0039-6257(81)90065-5

4. Huang JM, Callanan P, Callanan D, Wang RC: Rate of retinal detachment after early prophylactic vitrectomy for acute retinal necrosis. Ocul Immunol Inflamm. 2018, 26:204-7. 10.1080/09273948.2016.1202986

5. Risseeuw S, de Boer JH, Ten Dam-van Loon NH, van Leeuwen R: Risk of rhegmatogenous retinal detachment in acute retinal necrosis with and without prophylactic intervention. Am J Ophthalmol. 2019, 206:140-8. 10.1016/j.ajo.2019.05.023

6. Chang S, Young LH: Acute retinal necrosis: an overview . Int Ophthalmol Clin. 2007, 47:145-54. 10.1097/IIO.0b013e31803777bb

7. Park JJ, Pavesio C: Prophylactic laser photocoagulation for acute retinal necrosis. Does it raise more questions than answers?. Br J Ophthalmol. 2008, 92:1161-2. 10.1136/bjo.2008.147181

8. Sternberg Jr P, Han DP, Yeo JH, Barr CC, Lewis H, Williams GA, Mieler WF: Photocoagulation to prevent retinal detachment in acute retinal necrosis. Ophthalmology. 1988, 95:1389-93. 10.1016/s01616420(88)32999-4

9. Ahmadieh H, Soheilian M, Azarmina M, Dehghan MH, Mashayekhi A: Surgical management of retinal detachment secondary to acute retinal necrosis: clinical features, surgical techniques, and long-term results. Jpn J Ophthalmol. 2003, 47:484-91. 10.1016/s0021-5155(03)00139-4

10. Luo YH, Duan XC, Chen BH, Tang LS, Guo XJ: Efficacy and necessity of prophylactic vitrectomy for acute retinal necrosis syndrome. Int J Ophthalmol. 2012, 5:482-7. 10.3980/j.issn.2222-3959.2012.04.15 